\title{
CLASSIC PAPER
}

\section{The hazards of hospitalization *}

\section{E M Schimmel}

Qual Saf Health Care 2003;12:58-64

The occurrence of hospital-induced complications on a university medical service was documented in the prospective investigation of over 1000 patients. The reported episodes were the untoward consequences of acceptable medical care in diagnosis and therapy. During the 8-month study, 240 episodes occurred in 198 patients. In 105 patients, hospitalization was either prolonged by an adverse episode or the manifestations were not yet resolved at time of discharge. Thus, $20 \%$ of the patients admitted to the medical wards experienced one or more untoward episodes and $10 \%$ had a prolonged or unresolved episode. The severity of the 240 episodes was minor in 110 , moderate in 82 , and major in 48 , of which 16 ended fatally. Patients encountering noxious episodes had a mean total hospitalization of 28.7 days compared with 11.4 days in other patients. The risk of having such episodes seemed directly related to the length of time spent in the hospital. The number and variety of these reactions emphasizes the magnitude and scope of hazards to which the hospitalized patient is exposed. A judicious selection of diagnostic and therapeutic measures can be made only with knowledge of these potential hazards as well as the proposed benefits.

Correspondence to:

E M Schimmel, Department of Internal Medicine, Yale University School of

Medicine, and the

Grace-New Haven

Community Hospital, New

Haven, Connecticut, USA
$\mathrm{R}$ ecent medical progress has brought dramatic advances in methods of diagnosis and treatment. With each new advance, however, reports of adverse reactions have soon followed. The occurrence of occasional reactions is now considered to be an accustomed and almost predictable hazard rather than evidence of improper medical care.

These hazards have been called "the price we pay" for modern diagnosis and therapy. ${ }^{1}$ This new type of clinical pathology, documented in numerous reports of drug reactions and of the untoward effects of diagnostic or therapeutic procedures, has been catalogued under the title "Diseases of Medical Progress". 2 These reports and reviews usually cite only unusual reactions or those of major magnitude. The incidence of such "major toxic reactions and accidents" has been estimated as $5 \%$ in a series of hospital patients whose minor complications were unreported. ${ }^{1}$ An assessment

*This is a reprint of a paper that appeared in Annals of Internal Medicine, 1964, Volume 60, pages 100-110. of all untoward reactions, regardless of severity, is important to determine their total incidence and to indicate the cumulative risk assumed by the patient exposed to the many drugs and procedures used in his care. An evaluation of these hazards was the purpose of the work reported here.

\section{PLAN OF STUDY}

This investigation was planned as a prospective study of the type and frequency of hospital complications occurring in the patients of a university medical service. The project was designed for performance during the author's tenure as chief resident on that service and was a joint effort of all the medical house officers. To allow new staff members to become accustomed to the service, the project was begun on August 1, 1960, rather than during July. It was concluded on March 31, 1961 after more than 1000 patients had been studied. The investigation included all patients admitted to the Yale University Medical Service of the Grace-New Haven Community Hospital. This service, comprising three wards with a capacity of 80 beds, cares for private patients of the full-time university staff and for service patients attended by the ward interns, residents, and staff physicians.

The participating house officers sought and reported every noxious response to medical care occurring among their patients. These untoward events, complications, and mishaps are hereafter referred to as "episodes". An episode was included in this analysis if it resulted from acceptable diagnostic or therapeutic measures deliberately instituted in the hospital. Reactions were excluded if they arose from inadvertent errors by physicians or nurses, or if they occurred as postoperative complications or as nonspecific psychiatric disturbances. The adverse effects of previous treatment, occasionally the reason for hospitalizing a patient, were also omitted from this survey.

The symptoms, signs, and laboratory abnormalities of each episode were reported together with the suspected cause. Also noted were the duration of manifestations, their need for treatment, and their effect on the patient's subsequent hospital course. An episode was considered to be persistent if it had prolonged the patient's hospital stay or was unresolved at the time of his discharge. An episode was classified as minor if it was short and subsided without specific treatment, as moderate if it required significant treatment or if it prolonged hospitalization by a day or more, as major if it was life-threatening or contributed to death. 
Table 1 Type and severity of episodes

\begin{tabular}{|c|c|c|c|c|c|c|c|}
\hline \multirow[b]{2}{*}{ Type of episode } & \multirow{2}{*}{$\begin{array}{l}\text { No of } \\
\text { patients }\end{array}$} & \multirow{2}{*}{$\begin{array}{l}\text { No of } \\
\text { episodes }\end{array}$} & \multicolumn{3}{|c|}{ No of episodes of each grade } & \multirow{2}{*}{$\begin{array}{l}\text { No of persistent } \\
\text { episodes }\end{array}$} & \multirow[b]{2}{*}{ No of deaths } \\
\hline & & & Minor & Moderate & Major & & \\
\hline Reactions to diagnostic procedures & 29 & 29 & 10 & 6 & 13 & 17 & 4 \\
\hline Reactions to therapeutic drugs & 103 & 119 & 61 & 44 & 14 & 46 & 4 \\
\hline Reactions to transfusions & 24 & 31 & 17 & 11 & 3 & 9 & 0 \\
\hline Reactions to other therapeutic procedures & 24 & 24 & 11 & 11 & 2 & 14 & 2 \\
\hline Acquired infections & 21 & 23 & 2 & 7 & 14 & 15 & 6 \\
\hline Miscellaneous hospital hazards & 13 & 14 & 9 & 3 & 2 & 4 & 0 \\
\hline Totals & $198 *$ & 240 & 110 & 82 & 48 & 105 & 16 \\
\hline
\end{tabular}

\section{RESULTS}

\section{Incidence}

During the 8-month study, 1014 patients were admitted one or more times to the medical service for a total of 1252 admissions. The house staff recorded 240 episodes occurring in 198 different patients. Thus, $20 \%$ of the persons at risk suffered one or more episodes of medical complications in the hospital.

\section{Types of episodes}

The reported episodes discussed in this section were divided into six arbitrary categories for convenience in presenting the results. They are outlined in table 1 and given in greater detail in tables 2-4. The severity of the episodes was minor in 110 instances, moderate in 82, and major in 48, of which 16 ended fatally. The fatal episodes, listed in table 5, are more specifically described in a subsequent section of this report.

\section{Reactions to diagnostic procedures}

The 29 episodes enumerated in table 2 were associated with procedures or drugs used for diagnostic rather than therapeutic purposes.

Test drugs evoked six adverse responses including three hypotensive episodes and two local reactions to inadvertent extravasation of the test substance. Fever with a herpetic eruption was once noted in response to intravenous endotoxin used for clinical diagnostic investigation. None of these tests were fatal, although one sulfobromophthalein (Bromsulphalein (BSP)) reaction resulted in several hours of hypotension that was treated with a pressor agent. The patient had had a possible BSP reaction in the distant past and several subsequent innocuous tests, the most recent of which was 1 week earlier.

Premedication with atropine, meperidine, and pentobarbital resulted in hypotension before bronchoscopic examination. A second hypotensive episode followed procaine infiltration in preparation for a liver biopsy.

On six occasions endoscopic examination evoked adverse reactions including two fatalities that are discussed later.

Five episodes occurred after a tissue biopsy had been performed. Percutaneous liver biopsy was accomplished with the Vim-Silverman needle and gastric mucosa was sampled per os using a Wood's tube. Incisional biopsies of lymph node and muscle were obtained under local anesthesia.

Radiologic examinations using contrast substances were associated with five adverse reactions. Two patients, discussed below, died shortly after barium enema examinations. On two occasions carotid arteriograms caused large painful hematomas at the puncture sites, and a pneumoencephalogram resulted in an unexplained fever that subsided spontaneously.

Cardiac catheterization was twice complicated by infection or inflammation at the site of venous cut-down. One patient's hospitalization was prolonged by severe headache following lumbar puncture. Elicitation of tendon reflexes in a young man afflicted with systemic lupus erythematosus, diabetes
Table 2 Reactions to diagnostic procedures

\begin{tabular}{ll}
\hline Agent or procedure & Manifestation \\
\hline Test drugs & \\
Sulfobromophthalein (BSP) & Shock \\
Sulfobromophthalein (BSP) & Shock \\
Sulfobromophthalein (BSP) & Infiltration \\
Dehydrocholic acid (Decholin) & Infiltration \\
Histamine & Shock \\
Endotoxin & Fever and herpes \\
Premedications & \\
for bronchoscopy & Shock \\
for liver biopsy & Shock \\
Endoscopy & \\
Esophagoscopy & Perforation \\
Esophagoscopy & Perforation \\
Esophagoscopy & Shock \\
Cystoscopy & Cardiac arrest \\
Cystoscopy & Pyelonephritis \\
Bronchoscopy & Dysphagia \\
Biopsy & Hemorrhage \\
Liver & Peritonitis \\
Liver & Perforation \\
Stomach & Fistula \\
Lymph node & Paresthesia \\
Muscle & Cardiac arrest \\
Radiography & Shock \\
Barium enema & Hematoma \\
Barium enema & Hematoma \\
Carotid arteriogram & Fever \\
Carotid arteriogram & \\
Pneumoencephalogram & Phlebitis \\
Miscellaneous procedures & Cellulitis \\
Venous catheterization & Headache \\
Venous catheterization & Hemarthrosis \\
Lumbar puncture & Dermatitis \\
Reflex percussion & \\
Rebuck test & \\
\hline & \\
&
\end{tabular}

mellitus, and hemophilia caused a hemarthrosis, spontaneously resorbed. The Rebuck test, an investigative method of studying leukocyte function, produced a local eruption in an asthmatic patient.

\section{Reactions to therapeutic drugs}

One half of all the episodes in this series occurred as reactions to drugs used for treatment. The 119 episodes in this group were further classified according to their toxic, allergic, and metabolic manifestations. The episodes are enumerated in table 3 , and the responsible agents are cited in table 4.

The designation of toxic manifestations was used for the well-recognized, dose-related hazards peculiar to each drug. The manifestations of these 48 episodes included azotemia secondary to parenteral bacitracin, agranulocytosis after 5-fluorouracil, or ventricular arrhythmias with digitalis preparations. 
Table 3 Manifestations and severity of reactions to therapeutic drugs

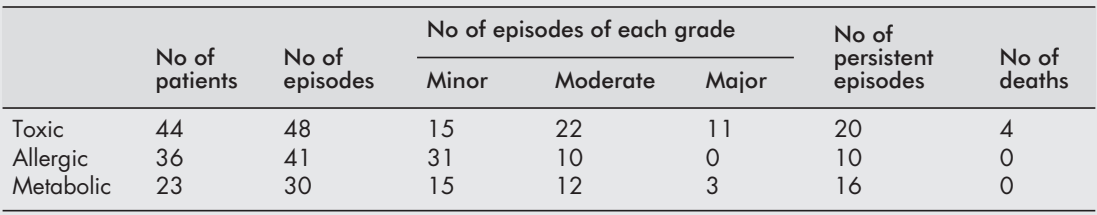

Table 4 Provocative agents and manifestations in reactions to therapeutic drugs

\begin{tabular}{|c|c|c|c|c|}
\hline \multirow[b]{2}{*}{ Agent or class } & \multicolumn{3}{|c|}{ No of episodes } & \multirow[b]{2}{*}{ Total nc } \\
\hline & Toxic & Allergic & Metabolic & \\
\hline Antimicrobials & & & & 35 \\
\hline $\begin{array}{l}\text { Penicillin and its } \\
\text { congeners }\end{array}$ & 1 & 18 & & \\
\hline Nitrofurantoin & 1 & 4 & & \\
\hline Tetracyclines & 2 & 2 & & \\
\hline Streptomycin & & 3 & & \\
\hline Amphotericin & 1 & & & \\
\hline Bacitracin & 1 & & & \\
\hline Isoniazid & 1 & & & \\
\hline Neomycin & 1 & & & \\
\hline $\begin{array}{l}\text { Hormone preparations } \\
\text { Insulin }\end{array}$ & & & 12 & 24 \\
\hline Steroids or ACTH & & & 12 & \\
\hline Antineoplastic drugs & 14 & & & 14 \\
\hline $\begin{array}{l}\text { Sedatives and } \\
\text { tranquilizers }\end{array}$ & & & & 11 \\
\hline Barbiturates & 1 & 5 & & \\
\hline Chloral hydrate & 1 & 2 & & \\
\hline Imipramine & & 1 & & \\
\hline Prochlorperazine & 1 & & & \\
\hline Anticoagulants & & & & 9 \\
\hline Heparin & 6 & & & \\
\hline Warfarin & 3 & & & \\
\hline Digitalis preparations & 7 & & & 7 \\
\hline Parenteral fluids & & & 4 & 4 \\
\hline Antihypertensives & & & & 3 \\
\hline Guanethidine & 1 & & & \\
\hline Hydralazine & & 1 & & \\
\hline Reserpine & 1 & & & \\
\hline Miscellaneous & & & & 12 \\
\hline Acetylsalicylic acid & 1 & 1 & & \\
\hline Atopine & 1 & & & \\
\hline Colchicine & 1 & & & \\
\hline Diphenhydramine & 1 & & & \\
\hline Diphenylhydantoin & & 1 & & \\
\hline lodides & & 2 & & \\
\hline Lidocaine & 1 & & & \\
\hline Lipomul, intravenous & & 1 & & \\
\hline Spironolactone & & & 2 & \\
\hline
\end{tabular}

Allergic responses were considered to be the classic signs of hypersensitivity associated with administration of the suspected drug. The signs in these 41 episodes were urticaria, maculo-papular eruptions, eosinophilia of over $7 \%$, or a fever of at least $101^{\circ} \mathrm{F}$.

The 30 episodes categorized as metabolic aberrations were those induced by hormone preparations, parenteral fluids, or a steroid antagonist. Insulin hypoglycemia was observed on 12 occasions, one of which was manifested by frank coma. Clinical and laboratory signs of hypercorticism were noted in several patients receiving natural or synthetic adrenal corticoids or adrenocorticotrophic hormone (ACTH). Two patients developed diabetes mellitus de novo and two demonstrated transient hypothyroidism on large doses of prednisone and ACTH. One episode of polyserositis occurred upon cessation of prednisone and was identified as an instance of the steroid withdrawal syndrome. Four persons developed electrolyte or volume disturbances while receiving parenteral fluids. Spironolactone treatment in two patients with Laennec's cirrhosis was followed by hepatic coma with associated electrolyte abnormalities.

As shown in table 4, antimicrobial or hormone preparations were responsible for 59, or half, of the 119 drug reaction episodes. The remaining episodes were due to antineoplastic drugs, sedatives or tranquillizers, anticoagulants, digitalis preparations, parenteral fluids, hypotensive drugs, and miscellaneous agents.

\section{Reactions to transfusions}

Transfusion of properly matched blood accounted for 30 episodes, and of plasma alone, for another. Fever of at least $101^{\circ} \mathrm{F}$ or shaking chills occurred in nearly half of these episodes, and urticarial or maculopapular eruptions occurred in one third. Pulmonary congestion, evidenced by dyspnea and rales, was noted in five instances that could not be attributed to over-transfusion because the ensuing hematocrit was less than 35\% each time, and the blood had been given over a period of an hour or more. Two patients developed hemolytic jaundice on the day after transfusion. Asthma was the major manifestation of one episode; headache or nausea occurred in conjunction with several others.

\section{Reactions to other therapeutic procedures}

Procedures intended primarily for therapy are described in this group although they sometimes also yielded diagnostic information. Thoracenteses were responsible for nine episodes; significant pneumothorax developed in seven instances, two of which required catheter drainage; and subcutaneous emphysema occurred once. Another complication of thoracentesis was a fatal episode of ventricular fibrillation. An intercostal nerve block also resulted in one episode of pneumothorax.

Bladder catheterization was followed by seven cases of symptomatic urinary tract infection and one episode of urinary retention. Three episodes of local phlebitis or cellulitis occurred as procedural complications of fluid therapy. Intermittent positive pressure breathing with 100\% oxygen induced carbon dioxide narcosis in a patient with chronic lung disease. A retention enema, given to relieve fecal impaction, led to shock in a middle-aged woman. The death of a patient with bleeding esophageal varices was related to tamponade with an esophageal balloon tube.

\section{Acquired infections}

The 23 episodes in this group were distinguished by a common manifestation-hospital-acquired infection-rather than by a common cause. The infecting organisms were hemolytic Staphylococcus aureus in 17, Candida albicans in 5, and Escherichia coli in one episode. The infections were manifested as bronchopneumonia in 9 patients and cutaneous abscess, furuncle or cellulitis in 7. Enterocolitis, thrush, and septicemia were each noted on two occasions. One patient developed persistent moniliasis of the urinary tract.

These infections occurred during treatment with antibiotics in 11 instances, with corticosteroids or ACTH in four, and with antineoplastic therapy in four others. Several patients were 
Table 5 Fatal episodes

\begin{tabular}{|c|c|c|c|c|}
\hline $\begin{array}{l}\text { Role of the } \\
\text { episode }\end{array}$ & $\begin{array}{l}\text { Agent or } \\
\text { procedure }\end{array}$ & Manifestation of the episode & $\begin{array}{l}\text { Age } \\
\text { (years) }\end{array}$ & Underlying disease \\
\hline Primary & Cystoscopy & Cardiac arrest & 69 & Chronic pyelonephritis \\
\hline Primary & Thoracentesis & Ventricular fibrillation & 76 & Congestive heart failure \\
\hline Precipitating & Esophagoscopy & Perforation & 50 & Cirrhosis \\
\hline Precipitating & Barium enema & Cardiac arrest & 89 & Tuberculous peritonitis \\
\hline Precipitating & Barium enema & Shock & 62 & Carcinoma of the lung \\
\hline Precipitating & Heparin (iv) & Retroperitoneal hemorrhage & 66 & Hypernephroma \\
\hline Precipitating & Blakemore tube & Asphyxia & 59 & Cirrhosis \\
\hline Contributory & Digoxin & Ventricular fibrillation & 40 & Rheumatic heart disease \\
\hline Contributory & Digitalis & Bigeminy & 60 & Myocardial infarction \\
\hline Contributory & $\begin{array}{l}\text { Digitoxin and } \\
\text { digoxin }\end{array}$ & $\begin{array}{l}\text { Multifocal premature ventricular } \\
\text { contractions }\end{array}$ & 69 & $\begin{array}{l}\text { Arteriosclerotic heart } \\
\text { disease }\end{array}$ \\
\hline Contributory & Penicillin & Staphylococcal enteritis & 85 & Pneumonia \\
\hline Contributory & Penicillin & Staphylococcal pneumonia & 62 & Myocardial infarction \\
\hline Contributory & $\begin{array}{l}\text { Penicillin and } \\
\text { streptomycin }\end{array}$ & Staphylococcal pneumonia & 68 & Tuberculous meningitis \\
\hline Contributory & $\begin{array}{l}\text { Tetracycline and } \\
\text { streptomycin }\end{array}$ & Staphylococcal septicemia & 28 & $\begin{array}{l}\text { Diabetic } \\
\text { glomerulosclerosis }\end{array}$ \\
\hline Contributory & $\begin{array}{l}\text { Steroids and } \\
\text { streptomycin }\end{array}$ & E coli pneumonia & 70 & Systemic granulomatosis \\
\hline Contributory & Sedatives & Staphylococcal pneumonia & 73 & Parkinsonism \\
\hline
\end{tabular}

receiving more than one of these agents when the nosocomial infection supervened. An isolated episode of $E$ coli pneumonia complicated the combined antimicrobial and steroid therapy of a systemic granulomatous disease. In four persons, each with a hospital-acquired staphylococcal infection, no specific predisposing therapy was incriminated.

\section{Miscellaneous hospital hazards}

The 13 episodes in this group occurred in patients who sustained injuries during their hospital regimens. Eight persons, while receiving sedatives, were hurt in falls, and one man was injured in a syncopal episode several minutes after receiving an injection. Four of these episodes resulted in significant hematomas, three in fractures of ribs, vertebral body, or femur, and two in lacerations requiring sutures. Four other cutaneous injuries were encountered: laceration during removal of adhesive tape, denudation from cellophane tape, sheet burns while positioning an elderly woman in bed, and a second degree burn of the buttocks due to a hot colloidal bath. An episode of ulnar palsy lasted several days after prolonged use of an armboard for intravenous therapy of a comatose young diabetic patient.

\section{Fatal episodes}

During the course of the study, 154 of the 1014 patients admitted to the medical service died in the hospital. Of these, 16 deaths were related to noxious episodes whose precise causal role was difficult to evaluate. For purposes of classification, the episodes were considered to be primary, precipitating, or contributory factors to the deaths associated with them. These episodes are listed in table 5.

Primary responsibility for the fatal outcome of two cases was ascribed to hospital procedures. In one, an obese hypertensive woman with hematuria developed cardiac arrest during cystoscopic examination. Autopsy revealed chronic pyelonephritis and moderate left ventricular hypertrophy without other significant disease. In the other, an elderly man with congestive heart failure was admitted with a massive pleural effusion, atrial fibrillation, and no evidence of myocardial infarction. During a thoracentesis performed to relieve dyspnea, the patient developed ventricular fibrillation after removal of $500 \mathrm{ml}$ of clear fluid; efforts at external defibrillation were unsuccessful.

In five patients who were seriously ill with fatal disease, an adverse episode was judged to be the immediate or precipitating cause of death. A middle-aged woman with decompen- sated cirrhosis was admitted for hematemesis and sustained a minor laceration of the esophagus during esophagoscopy. Mediastinal emphysema developed, followed by general deterioration and death in hepatic coma the next day. At autopsy, mediastinitis was not found and the esophageal perforation was deemed a precipitating factor in death from hepatic failure.

Two patients died shortly after barium enemas, although autopsy revealed no evidence of bowel perforation in either. One man died of cardiac arrest in the fluoroscopy suite while evacuating the barium. The second developed signs of pancreatitis and went into shock after returning to the ward; the debilitating role of preparatory purges probably played a major role in this episode.

A patient with polycythemia, treated with intravenous heparin for probable cavernous sinus thrombosis, died from massive retroperitoneal hemorrhage arising in a previously undiagnosed hypernephroma.

The death of one man with esophageal varices followed successful control of hemorrhage with esophageal balloon tamponade. A few hours after intubation, the patient became dyspneic necessitating transection and removal of the tube; the patient was resuscitated but succumbed shortly thereafter. It was discovered that the gastric balloon had ruptured allowing the esophageal balloon to rise and temporarily obstruct the hypopharynx, causing asphyxia.

Nine episodes, all associated with drug administration, were held to be contributory to death. Digitalis preparations were incriminated for three situations in which ectopic ventricular rhythms developed shortly before death. Although underlying cardiac disease provided sufficient cause for these arrhythmias, the drugs were assigned contributory responsibility.

Six persons died with hospital-acquired infections, five of which were staphylococcal. The clinical diagnosis of $E$ coli pneumonia, made in the sixth, was confirmed at autopsy. The one man not receiving antibiotics before infection was treated with various sedative drugs and acquired a penicillin-resistant staphylococcal pneumonia.

\section{Age}

The mean age of the 198 patients involved in these episodes, 53 years, was identical to the mean age of the 1014 patients admitted to the medical service during the 8-month study. The mean age of the patients in the two categories cited below was significantly $(\mathrm{p}<0.05)$ greater than that of the remaining 
patients encountering adverse episodes. One of these categories was patients with reactions to therapeutic procedures in whom the mean age was 62 years; the other was those with miscellaneous hospital hazards, who averaged 65 years.

\section{Length of hospitalization}

The average length of hospitalization is usually reported as the time, in days, per admission. For the 1252 admissions of this series, this average was 12 days. About 20\% of these admissions, however, were readmissions of patients already entered in the series; for the 1014 different patients admitted during the 8-month study period the average total hospitalization per person was 14 days. This average hospitalization time per person was 28.7 days for the 198 patients who had untoward episodes, and 11.4 days for the 816 patients who had no such complications. The difference in these two groups is not attributable to readmissions alone since about $20 \%$ of the patients in each group had had readmissions during the study period, nor is it attributable, as noted below, to the episodes themselves.

\section{Prolongation of hospitalization}

A patient's hospitalization was sometimes extended as a result of an adverse episode, but the additional time increment was difficult to assess precisely. When these episodes prolonged a patient's hospitalization, they usually added only a few extra days, and a delay of as long as a week occurred in less than a dozen patients. In 89 patients, $9 \%$ of the 1014 surveyed, the hospital stay was extended one or more days by medical complications. Thus, the delay due to the episode itself was too brief to account for more than a few days of the increased time spent in the hospital by patients who had such episodes.

It seems likely, therefore, that the risk of these episodes was related to the length of time spent in the hospital.

\section{Persistent episodes}

Of the 89 patients whose hospitalization was prolonged, 23 sustained episodes that were unresolved at the time of discharge. In 16 other patients, not delayed by an adverse reaction, some persistent manifestations of the episode were evident on discharge. Thus, persistent episodes (as defined earlier) occurred in 105 patients, $10 \%$ of the total surveyed, and the episodes were unresolved in 39.

\section{DISCUSSION}

The present investigation has evaluated the hazards of hospitalization by determining the adverse effects on the patient of all the diagnostic and therapeutic measures instituted on his behalf. No attempt has been made to assess the relative safety of individual drugs or procedures; such an estimate would require tabulation of how many times each measure was used during the study period. The focus of this study was not the incidence of reactions to specific agents, but the cumulative risk to the patient who accepts the whole of our medical care.

The number of adverse episodes identified during such a study will depend on the criteria for their definition and on the diligence with which they are sought. The undesirable reactions defined as episodes in this study were those considered by the physician to be harmful, in some way, to the patient. The innocuous and largely unavoidable discomforts of needle punctures, endoscopic examinations, preparation for radiologic studies, and biopsy procedures were not per se regarded as deleterious. Other events excluded from the study were potentially harmful situations that were detected before noxious effects developed. Such situations arose, for example, in patients receiving broad-spectrum antibiotics when the bacterial flora of the sputum or stool was asymptomatically replaced by staphylococci or monilia. Similarly omitted was the detection of excessive hypoprothrombinemia occurring during anticoagulation but without hemorrhagic manifestations. Events such as these often led to appropriate changes in management of the patient, but were not considered as "episodes" for the purpose of this study.

Various toxic manifestations of drug administration were excluded if the signs were deliberately invoked as guides to therapeutic dosage. Among these were dryness of the mouth with belladonna, anorexia or nausea with digitalis, and prolongation of the Q-T interval with quinidine. Insulin hypoglycemia, by contrast, was always included as an episode rather than a useful sign in determining dosage.

In addition to these problems of definition, the onerous effects of diagnosis and treatment often had to be differentiated from the course of the underlying disease. During treatment of bacterial infection with antibiotics, the reappearance of fever may represent either a suppurative complication or a manifestation of allergy. In the treatment of congestive heart failure with digitalis, premature ventricular contractions may be the result of further cardiac decompensation or of drug toxicity. These clinical situations present diagnostic challenges as well as therapeutic dilemmas that often remain unresolved.

For all these reasons, the distinctions used to define the episodes of this series were not always sharp. Ultimately, clinical judgment was required in applying the basic criterion that "episodes" were superimposed on the disease as noxious complications of deliberately chosen medical procedures.

The series of episodes reported here is probably incomplete and has more omissions than those just described. Some minor events may have been unreported by the patient, noted but not reported by the nurse, or inadequately sought by physicians who may have failed to ask the right questions, examine the affected area, or request the appropriate laboratory test. In several instances a previously undetected episode was discovered because the patient mentioned it to other patients or to ward attendants, or because the physician accidentally encountered information in the nurses' notes or overheard their oral reports. Certain major events could not be cited in this study if they occurred after the patients left the hospital. Such events could include the subsequent development of homologous serum jaundice after transfusion, smoldering pyelonephritis after catheterization, or delayed allergic reactions becoming manifest soon after discharge. Also possible are the distant reactions of patients sensitized to some drug or antigen in the hospital but not challenged by the offending agent until some future time.

The economic loss and emotional disturbance suffered by many patients were beyond the scope of this study, yet cannot be considered insignificant complications of their medical care.

Within the bounds of observation used in this study, deleterious episodes befell $20 \%$ of all patients admitted to the service, and were major in $4.7 \%$. The latter figure is similar to the reported 5\% incidence of "major toxic reactions and accidents" found on another university medical service. ${ }^{1}$ Such major episodes are readily noted and documented because their pernicious effects are so striking. An important aspect of the present investigation, however, was a detection of the entire spectrum of nosocomial disorders, by documentation of all untoward incidents with emphasis on the less dramatic events. An awareness of this spectrum is critical to the physician dedicated to optimal patient care. Because the major, moderate, or minor severity of an episode may simply reflect the stage at which the disorder comes to medical attention, the observed abnormalities in any episode may be the final expression of an unimportant side effect, or the beginning of a more serious reaction. An allergic response to penicillin, for example, may not go beyond an initial maculopapular eruption or may progress to exfoliative dermatitis. Similarly, a furuncle may be the sole manifestation or, at times, the harbinger of septicemia, in a hospital-acquired staphylococcal 
infection. The outcome of many episodes cannot be determined when they are first detected; moderate and major reactions can develop from minor episodes.

The identification of these lesser disorders therefore has prophylactic and therapeutic significance because their progression may be halted by appropriate changes, instituted at the earliest signs of adverse effects. Detection of a persistent significant bacteriuria following bladder instrumentation may lead to treatment of an asymptomatic patient, thus possibly preventing overt renal damage or other complications. Discovery of early signs of drug toxicity or allergy may end an incident by withdrawal of the agent or prevent subsequent reactions by avoiding its future use.

The patients who sustained adverse episodes during their hospital stay were similar to other patients in most respects. They suffered from similar diseases, were of the same mean age, and were readmitted to the medical wards with the same frequency. The major feature that distinguished them from other medical patients was the length of their hospitalization. The patients with adverse episodes during the 8-month study were hospitalized for an average of 4 weeks while the remaining medical patients were in the hospital for an average of 1.5 weeks. It appears that the long hospital stay was the factor predisposing to the occurrence of adverse episodes. Although the patient with longer hospitalization may have been more seriously ill or more vulnerable to hospital hazards, there is no reliable way to so compare different patients with various diseases. With increasing severity of sickness, the patient may be more vulnerable because he receives more treatment, more hazardous treatment, or simply remains longer in the hospital. For whatever reason, the high incidence of untoward episodes was related to the length of stay in the hospital and thus reflects the general hazards of hospitalization.

The many reactions reported here, and the variety of drugs and procedures incriminated, emphasize the need to hold all measures suspect. In addition to recognized dangers, each new drug or procedure bears potential hazards that are not immediately apparent and that may be discovered, like thalidomide-induced phocomelia, only after terrible harm is done. In the strategy of modern medical management, it becomes increasingly difficult to justify equivocal procedures with the comment, "It can't hurt!" The probable benefit of each test or treatment must be weighed against its possible risk.

The classical charge to the physician has been primum non nocere. Modern medicine, however, has introduced potent procedures than cannot always be used harmlessly. To seek absolute safety is to advocate diagnostic and therapeutic nihilism at a time when the scope of medical care has grown beyond previous imagination and power. The dangers of new measures must be accepted and are generally warranted by their benefits, and should not preclude their useful employment. Until safer procedures evolve, however, physicians will best serve their patients by weighing each measure according to its goals and risks, by choosing only those that have been justified, and by remaining prepared to alter the procedures when imminent or actual harm threatens to obliterate their good.

\section{ACKNOWLEDGEMENT}

The author gratefully acknowledges participation of the following members of the house staff in the study: Roger P Atwood, J Alfred Berend, A Russell Brenneman, Robert W Chambers, Richard A Chase, Richard A Cooper, Alan S Dana Jr, H. Bruce Denson, William P Edmondson, Thomas F Ferris, Stanley Friedman, Lawrence A Frohman, John A Goffinet, Alexander F Goley, George F Grady, Lester H Grant, John P Hayslett, Francis J Klocke, Jack Levin, Norman S Lichtenstein, Lewis B Morrow, J Thomas Okin, Chase N Peterson, John P Phair, Emanuel T Phillips, Jerrold M Post, Robert L Scheig, John A Simpson, N Sheldon Skinner, Leon G Smith, George F Thornton, Robert M Vogel, and Bobby T Wood.

\section{REFERENCES}

1 Barr DP. Hazards of modern diagnosis and therapy-the price we pay. JAMA 1955;159:1452.

2 Moser RH. Diseases of medical progress. N Engl J Med 1956;255:606.

\section{COMMENTARY}

\section{BACK TO THE FUTURE}

In June 1964, while preparing to start my internship on the medical service of the Yale-New Haven Hospital, I received a welcoming letter from the chief resident advising that the new interns begin their orientation by reading a recent article, "The hazards of hospitalization" by Elihu Schimmel. ${ }^{1}$ This now classic report was the product of Schimmel's year as chief resident at Yale in 1960-1 when he designed a research project to involve all 33 members of the internal medicine house staff. While Robert Moser had earlier coined the term "diseases of medical progress" and a previous study estimated a 5\% rate of "major toxic reactions and accidents" on a university medical service, the Yale study was the first prospective assessment of these risks. Adverse events were identified from report forms that were attached each day to the front of patients' charts and were filled out by the attending house officers. Importantly, episodes were included in the analysis if they "arose from acceptable diagnostic or therapeutic measures deliberately instituted in the hospital", and complications "were excluded if they arose from inadvertent errors by physicians or nurses". The startling discovery that $20 \%$ of patients admitted to the medical service had one or more complications, even in a leading teaching hospital, was told and retold many times to succeeding generations of that hospital's house staff.

The Schimmel report, largely forgotten except by physicians who trained at Yale in the 1960s, now appears as a landmark in the measurement of the quality of care. When this paper was published, Weed's problem oriented medical record and Donabedian's taxonomy for quality were still in the future, Lown had only recently introduced electrical cardiac defibrillation, and hospitals did not yet have intensive care units. The issues addressed in the Schimmel report were not rooted in concerns about the cost of health services - the cost of a day in the hospital at that time was something less than \$70. Medical errors and mistakes were also not a particular focus; indeed, the belief that the quality of medical care in this facility was exemplary lay behind its power.

The impetus for the Schimmel report undoubtedly owed much to the singular leadership of a remarkable department chairman, Paul Beeson, who, while nurturing a large academic department emphasizing basic science, used his charisma and mystique to model humanism and caring in medicine. Beeson exemplified humility, graciousness, and diligence that are sensitively portrayed in his biography by Rapport. ${ }^{2}$ In his own work Beeson had called attention to the hazards of the urinary catheter that sometimes caused infections that were difficult to treat and advised that there should be good indications for its use. ${ }^{3}$ (Yale house officers were advised wisely to avoid the use of a urinary catheter unless absolutely necessary.) Beeson was distressed by the risks of adverse outcomes that frequently result from even the best care. His background was unusual in that he had actually spent several years in general practice with his father and brother in Ohio before beginning his academic career. As a towering leader in medical education extending over four decades, including his appointment as the Nuffield Professor of Medicine at Oxford and recognition as an Honorary Knight Commander of the Most Excellent Order of the British Empire, he played a central role in promoting the 
hospice movement in the US, served as a driving force in the new field of geriatrics, and became an ardent member of the Physicians for Social Responsiblity.

One of Beeson's initiatives at Yale that followed the publication of "The hazards of hospitalization" and that was motivated by his increased concerns about the conditions of patient care resulted in a book by Duff and Hollingshead "Sickness and Society", ${ }^{4}$ published in 1968, that was highly critical of hospital care. In a review, Beeson himself criticised the book for its sensationalist style and other deficiencies after it was described in an article in McCall's magazine entitled "Hospital. Enter at your own risk." Beeson's ambivalence-he conceded that "there are bases for many of the things the authors deplore"-parallels and resembles the responses of many thoughtful physicians today to the 1999 Institute of Medicine report "To Err is Human: Building a Safer Health System" and the resulting flap in the lay media. ${ }^{5}$ The Schimmel report, in contrast, was not accompanied by press releases and attracted little attention-perhaps because, in 1964, the media had not yet discovered the public's appetite for medical news.

Sherwin Nuland, a Yale surgeon and gifted medical writer, noted that the Schimmel study provoked a great deal of thought but little else, certainly no demonstrable changes, either at Yale or elsewhere. ${ }^{6}$ The rate of injury in the 1960-1 study may even have been higher if adverse events due to inadvertent errors had not been specifically excluded. A similar study at Boston University Medical Center nearly two decades later in 1979 found an even higher rate of iatrogenic illness ( $36 \%$ of 815 patients admitted to the medical service). ${ }^{7}$ These investigators also did not report events due to errors and believed their criteria for injury to be conservative. How are these high rates of injury determined prospectively 30-40 years ago to be viewed in relation to the lower rates $3.7 \%$ and $2.9 \%$, respectively) from implicit reviews of medical records in the retrospective New York State and Utah-Colorado studies in 1984 and 1992, respectively? ${ }^{89}$ These more recent studies included only injuries that prolonged hospitalization or caused disability at the time of discharge, but the results are more broadly representative of hospitals in general owing to the random sampling methods used. It is striking that many, if not most, of the adverse events in the Schimmel study were due to now outmoded drugs or procedures, factors that sharply limit its modern relevance. Interestingly, Schimmel found that $10.4 \%$ of patients had episodes of moderate or major severity - that is, using definitions similar to the New York State study. Is the rate declining or are the risks actually increasing for our most ill patients? The answers to both these questions are probably "yes". There is a clear opportunity for an ambitious investigator to redo the Schimmel study in a contemporary hospital.
In the 1960s the Schimmel report had a clear message for the house staff. Physicians became more aware that the risks of hospitalization had to be factored into the decision to admit patients for hospital care. However, the changed nature of hospital care over the past several decades-leading to earlier discharges, shorter lengths of stay, and increased home therapy-as well as ageing of the population, more immunocompromised patients, and more aggressive treatments and surgical procedures, has both reduced and complicated the recognition of hospital related adverse events and expanded the nature of adverse events to include all episodes related to health care, regardless of venue.

A lesson from the Schimmel study for the current concerns about patient safety and medical error is the need to monitor adverse events continuously as the foundation of injury prevention and for this process to take place as a normal procedure at the patient's bedside by the caregivers themselves. The Yale study was based on voluntary reporting by a committed and dedicated house staff and shows that this process can work quite well with the right kind of leadership. This report was the work of insiders at the sharp end of patient care, often overworked and tired house officers. It is disappointing that this lesson has still not been learned. External mandatory reporting has not worked well..$^{10}$ There is now great interest in developing new voluntary reporting systems, and Schimmel showed one way such a programme can work.

\section{J P Burke}

370-9th Avenue, Suite 204, Salt Lake City, UT 84103, USA; Idjburke@ihc.com

\section{REFERENCES}

1 Schimmel EM. The hazards of hospitalization. Ann Intern Med 1964;60:100-10.

2 Rapport R. Physician: the life of Paul Beeson. Fort Lee, NJ: Barricade Books, 2001.

3 Beeson PB. The case against the catheter. Am J Med 1958;24:1-3.

4 Duff RS, Hollingshead AB. Sickness and society. New York: Harper and Row, 1968

5 Brennan TA. The Institute of Medicine report on medical errors: could it do harm? N Engl J Med 2000;342:1123-5.

6 Nuland SB. The hazards of hospitalization. The Wall Street Journal, 2 December 1999.

7 Steel K, Gertman PM, Crescenzi C, et al. latrogenic illness on a general medical service at a university hospital. N Engl J Med 1981;304:638-42.

8 Brennan TA, Leape LL, Laird NM, et al. Incidence and nature of adverse events and negligence in hospitalized patients. Results of the Harvard Medical Practice Study I. N Engl J Med 1991;324:370-6.

9 Thomas EJ, Studdert DM, Burstin HR, et al. Incidence and types of adverse events and negligent care in Utah and Colorado. Med Care 2000;38:261-71.

10 Leape LL. Patient safety: reporting of adverse events. N Engl J Med 2002;347:1633-8 